\title{
DbDMAD: a Database of DNA Methylation in Human Age-related Disease
}

\author{
Wei Zhang ${ }^{\mathrm{a}}$, Chang Linghu ${ }^{\mathrm{b}}$, Juhua Zhang ${ }^{\mathrm{c}, *}$ \\ ${ }^{a, b, c}$ School of Life Science and Technology, Beijing Institute of Technology, Beijing, China
}

\begin{abstract}
DNA methylation plays a variety of crucial roles in cell division, proliferation, development of aging life, development of genetic diseases related to uniparental disomy, and carcinogenesis. DNA methylation can be probed by HPLC and gene chip which is very helpful to the high-through methylation test. In recent years many published articles reported that DNA methylation may be linked with human aged disease. Mining and integration of DNA methylation in human aged disease can be beneficial to novel biological discoveries. There has not been DNA methylation database repository which is exclusive for human aged disease. Therefore, we developed dbDMAD: a database of DNA methylation in human aged diseases, there are two purposes of it, one is to store DNA methylation in human aged disease datasets which were obtained from laboratory experiments, another is to find the relationship of different aged diseases. This is the first release of dbDMAD in which users can find 12 kinds of human aged diseases and relevant DNA methylation information. It can be searched by disease name and gene ID. This database also includes a visualization tool named ChainMap, by which the map of methylation pathway can be shown.
\end{abstract}

Index Terms: dbDMAD; DNA Methylation; Aged Disease; Database

(C) 2012 Published by MECS Publisher. Selection and/or peer review under responsibility of the International Conference on E-Business System and Education Technology

\section{Introduction}

DNA methylation refers to the addition of a methyl $(\mathrm{CH} 3)$ group to a DNA molecule [1]. In human somatic cells, DNA methylation preferentially involves the 5' cytosine in CpG dinucleotides [2]. The mediation of DNA methylation is a family of DNA methyltransferases which includes Dnmt1, Dnmt3a and Dnmt3b. Dnmt1 is maintenance Mtase which primarily replicates methylation patterns, while Dnmt3a and Dnmt3b are capable

\footnotetext{
* Corresponding author:

E-mail address: ${ }^{\circ}$ ihzhang@bit.edu.cn
} 
of methylating previously unmethylated DNA, referred to as de novo methylation [3]. DNA methylation has important roles in differentiation, $\mathrm{X}$ chromosome inactivation, genomic imprinting, maintenance of chromatin structure, and suppression of "parasitic" DNA [4]. Nowadays, a lot of analysis techniques to probe DNA methylation in human cell samples, such as HPLC, Methylation-specific PCR, and Methylation-specific gene chip. Different techniques provide information on DNA methylation at different levels, spanning from genome-wide methylation content to methylation of single residues in specific genes [5]. DNA methylation has two types: hypermethylation and hypomethylation. Both of them are occurring with aging. If DNA methylation level is lower than the normal level, which will be considered as hypomethylation. During the early molecular abnormalities, hypomethylation is one of the potential detections of cancer biomarkers [6]. Moreover, Hypermethylation of 5'-CpG islands of cancer suppressor genes can silence the gene and serve as an alternate to mutations [7]. So the most immediately potential usage of $\mathrm{CpG}$ hypermethylation will be as cancer biomarkers [8].

It has been found that DNA methylation was not only related with cancer, but also related with human aged diseases, such as arteriosclerosis, hypertension, etc. For this reason, we developed dbDMAD. The first use of it is to store DNA methylation, but it especially focuses on the data which owns information of the relationship between DNA methylation and human aged disease. It will be of great help both in the study of the DNA methylation and the roles of this modification in human aged disease. To establish this database, we manually curated 560 public articles in PubMed which had DNA methylation in 12 kinds of human aged disease information and created it named 'dbDMAD'. Two search options were provided for advanced searches, namely disease name and gene ID. Furthermore, dbDMAD provides a visualization tool: ChainMap. When you click ChainMap, you can see the pathogenic pathway vividly. This tool can help users to find the connections of different human aged diseases.

\section{Data Source}

Firstly, we first searched PubMed by keywords such as 'DNA methylation and heart disease', 'DNA methylation and diabetes' and so on. Then we downloaded the search results that had been recorded before April 2010 from the National Center for Biotechnology Information (http://www.ncbi.nlm.nih.gov/ ). From this search, we obtained about 560 papers which contained those keywords. Next we curated the data manually. The database includes hyperlinks to the original PubMed articles, and researchers who are interested in the article can get the details through the link.

At last, dbDMAD includes 432 gene's information. According to the relationship between disease and gene or environment factor, for each article we drawn chain map to help the users to see the pathway about human aged disease vividly.

Not only do we use our manual data source, but also use the public methylation data of human which formed into a public database-MethDB( http://www.methdb.de ). We extracted about 19081 data form MethDB, and these data were about human tumor. The data from MethDB had more detailed information about the DNA sequence and experiment results. We can use these data to design a model which can predict the methylation state of DNA.

\section{Database Utility}

dbDMAD provides two types of searching models on its search page (Fig.1A). One is the disease name search, another is gene ID search. Users can select one disease name or gene ID to browse page. Search and browse results list basic information (Fig.1B), such as related disease, gene ID, methylation style (hypermethylation or hypomethylation) and the original article name. More detailed information for each disease can be accessed by clicking the detailed link, as shown in fig. 1C. Detailed information contains the pathogenic site, the inducing factor, the pathogenic result and the sample of laboratory experiments, etc. For 
example, users can enter the database first page 'search by disease name', then choose the arteriosclerosis in the search box, and then proceed. The result page will show 12 results about this disease. Each result will be listed in one row. As the first row shows, the related gene is $\mathrm{P} 21^{\mathrm{ras}}$, methylation style is hypomethylation. If click the detail column, it will enter the detail page, from this page, users can find that the pathogenic site is vascular endothelial cells, the inducing factor's homocysteine, the pathogenic result is vascular endothelial cells damage, and the sample of laboratory experiment is human umbilical vein endothelial cells and human aortic endothelial cells. Users also can know the methylation sites are P2 ${ }^{\text {ras }} \mathrm{C} 17, \mathrm{C} 18, \mathrm{C} 20$, and $\mathrm{C} 37(\mathrm{C}$ means the methylated cytosine). dbDMAD also includes a visualization tool named ChainMap, by which methylation pathway will be shown vividly. We also give the same example as above shows. Fig. 1D is the map of the pathway.

dbDMAD:a database of DNA methylation in human aged disease
Search by Disease Name Homepage Database Software Publications Documents
Please Select \& Validated Disease Name -
Query examples : Select the Disease Symbol

\section{Search by Target Gene}

Please Select A Validated Gene Nane *

Query examples : Select the Gene Symbol

\begin{tabular}{|c|c|c|c|c|c|c|c|}
\hline \multicolumn{2}{|l|}{ B } & \multirow[t]{2}{*}{ Homepage } & \multirow{2}{*}{ Article Name } & ations & Document & & \multirow{2}{*}{$\begin{array}{l}\text { People } \\
\text { Detail }\end{array}$} \\
\hline Disease Name & Gene Name & & & \multicolumn{2}{|c|}{ Methylation Style } & Year & \\
\hline arteriosclerosis & P21ras & $\begin{array}{c}\text { Inhibition of growth and p2 } \\
\text { in vascular endothelial cells } \\
\text { but not cy }\end{array}$ & $\begin{array}{l}\text { is methylation } \\
\text { homocysteine }\end{array}$ & hypc & thylation & 1997 & More. \\
\hline arteriosclerosis & EC-SOD & $\begin{array}{l}\text { Local hypomethylation in ath } \\
\text { in rabbit ec-sod }\end{array}$ & $\begin{array}{l}\text { gesclerosis found } \\
\text { gene }\end{array}$ & hyp & thylation & 1999 & More. \\
\hline arteriosclerosis & global DNA & $\begin{array}{r}\text { Mitogen-induced P53 dowenr } \\
\text { vascular smooth muscle ce } \\
\text { health tunic }\end{array}$ & $\begin{array}{l}\text { gulation precedes } \\
\text { migration from }\end{array}$ & hypc & thylation & 2001 & More. \\
\hline arteriosclerosis & MTHFR & $\begin{array}{l}\text { A common mutatic } \\
5,10 \text {-methylenetera-hydro } \\
\text { gene affects genomic D }\end{array}$ & $\begin{array}{l}\text { in the } \\
\text { late reductase } \\
\text { A methylati }\end{array}$ & hyp & tion & 2001 & More. \\
\hline arteriosclerosis & global DNA & $\begin{array}{r}\text { DNA methylation smooth } \\
\text { atherogene }\end{array}$ & uscle cells and & hypo & thylation & 2003 & More. \\
\hline arteriosclerosis & APOE & $\begin{array}{r}\text { DNA methylation polymorph } \\
\text { histological sign of atheros } \\
\text { lacking apo }\end{array}$ & $\begin{array}{l}\text { ms Precede Any } \\
\text { lerosis in mice }\end{array}$ & hyp & thylation & 2004 & More. \\
\hline arteriosclerosis & global DNA & The impact of metabolism or & DNA methylation & hypc & thylation & 2005 & More.. \\
\hline arteriosclerosis & МСТ 3 & $\begin{array}{l}\text { Inactivation of monocarbo } \\
\text { MCT3 by DNA methylation }\end{array}$ & $\begin{array}{l}\text { late transporter } \\
\text { atherosclerosis }\end{array}$ & hype & thylation & 2005 & More.. \\
\hline arteriosclerosis & ADOE & $\begin{array}{r}\text { Plasma S-Adenosylhomocy } \\
\text { biomarker of atherosclerosis } \\
\text { in apolipro }\end{array}$ & $\begin{array}{l}\text { teine is a better } \\
\text { an homocysteine }\end{array}$ & hy & ion & 2008 & More. \\
\hline
\end{tabular}




\section{Details for this article $\rightarrow \rightarrow$}

C

Publled ID : 9312159

Disease :

Related Gene :

Pathogenic Site :

Inducing Factor :

Pathogenic Result :

Experiment Samples:

Sample Species :

Methlation Sites :

Pathway Description : arteriosclerosis

P21ras

\section{vascular endothelial cells}

hmocysteine

vascular endothelial cells damage

umbilical vein endothelial cells \&aortic endothelial cells

human

\section{P21 C17,C18,C20,C37}

homocysteine decreased the methylation of P21ras, then the P21ras-MAP kinase activity decreased, then makes vascular endothelial cells damage.

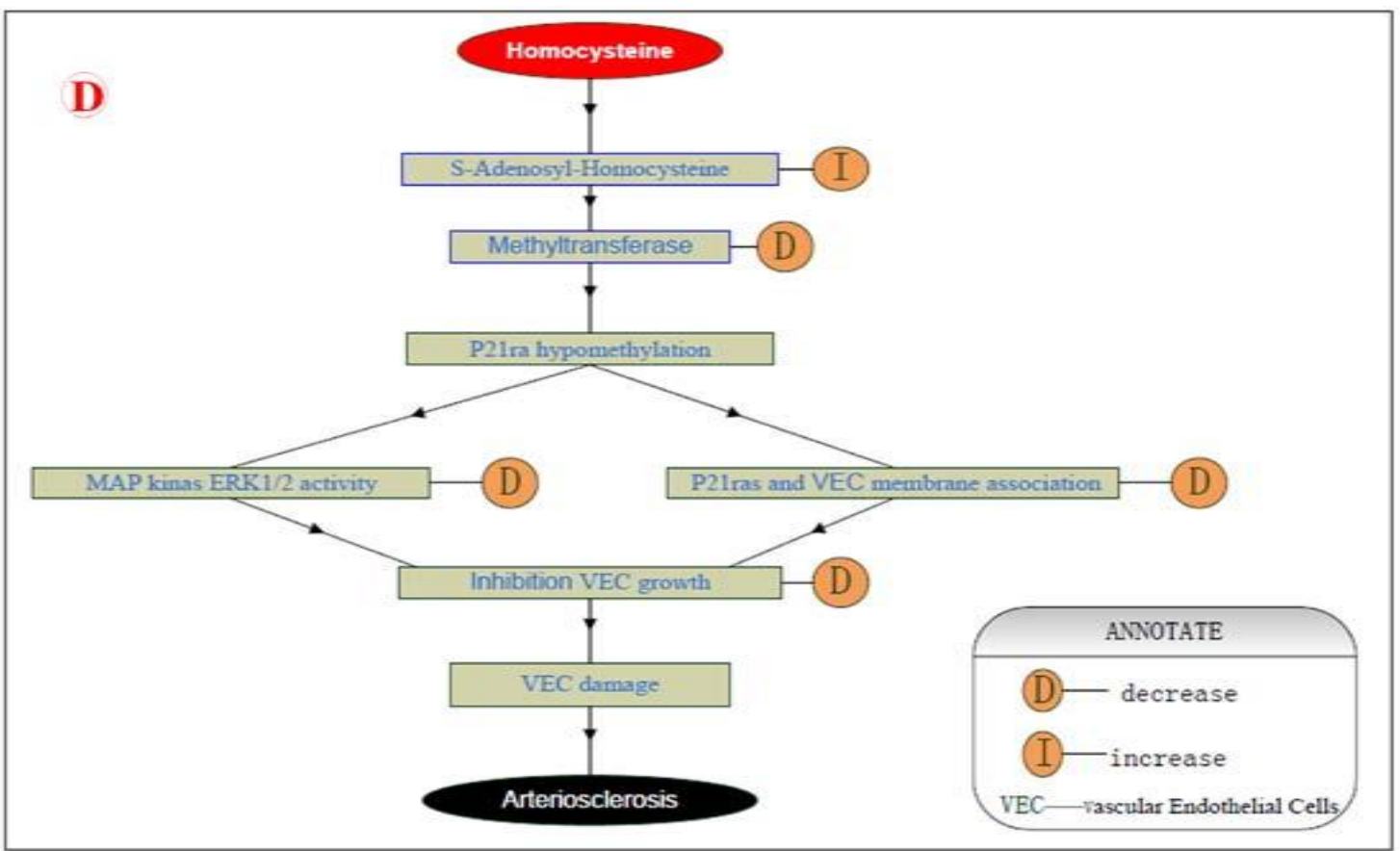

Fig. 1. The interface of dbDMAD.

(A) Search page. It can be searched by disease name or related gene.

(B)Result page for search. It provides a list of basic article information.

(C) A part of an example detail record. In the top of this page where has a hyperlink to PubMed web. In the below has a ChainMap button.

(D) An example of ChainMap page which shows the arteriosclerosis nosogenetic pathway. 


\section{Database Implementation}

dbDMAD is running on an Apache Tomcat web server and a MySQL server. The front page was built using PHP. Maps in the ChainMap page were drawn by Microsoft Office Visio 2007.

\section{Discussion and Future Development}

In order to provide a central resource for biologists in the human aged disease research, we developed dbDMAD, a database system aimed at providing a comprehensive resource of DNA methylation information and their relationships to kinds of aged disease. The goal of the dbDMAD database project was to construct a platform for DNA methylation in human aged disease that would be interrelated with each other. In order to help users to see the pathogenic pathway in each search result, we developed a visualization tool ChainMap. In the future, we will add a tool which can find out the same factor in different maps. In this way, users may chase down the contact of different human aged diseases easily.

There are four databases about methylation that have been reported in publication. The first is HHMD, which focuses on the histone modification [9]. The second is methDB, which stores information about DNA methylation

data from experimental procedure [10]. The third is PubMeth, which focuses on the publish articles about the methylation information [11], and the last is MethyCancer, which includes the human DNA methylation and cancer information [12]. Table1 shows the detailed information about these four databases and lists every database concerns and special tools information for comparison.

Table 1. Atabase Comparative Information

\begin{tabular}{|c|c|c|}
\hline DATABASE & CONCERNS & SPECIAL TOOLS \\
\hline HHMD & $\begin{array}{l}\text { Histone modification, including histone } \\
\text { methylation information }\end{array}$ & HisModView: can show the histone modification map \\
\hline MethDB & $\begin{array}{l}\text { DNA methylation, including sample information } \\
\text { and experiment information }\end{array}$ & $\begin{array}{l}\text { On-line submit system[13]:allows public to directly enter new } \\
\text { data into MethDB. } \\
\text { Distributed Annotation System[14]:allows the epigenetic data } \\
\text { sored in MethDB into the network of biological database. }\end{array}$ \\
\hline dbDMAD & $\begin{array}{l}\text { DNA methylation in human aged disease } \\
\text { information. }\end{array}$ & ChainMap: can show the pathogenic pathways. \\
\hline PubMeth & The publish articles of DNA methylation & None \\
\hline MathyCancer & $\begin{array}{l}\text { The relationship between DNA methylation and } \\
\text { cancer. }\end{array}$ & CGPi130[15]: predicte the $\mathrm{CpG}$ islands methylation states. \\
\hline
\end{tabular}

Nowadays, the data volume in our database is smaller than MethDB or HHMD, but in the future we will increase more kinds of human aged disease. The data about DNA methylation status can help us to establish a predicting machine which can help to predict the other DNA methylation states which hasn't detected before. Like MethyCancer CGI prediction tools, we will develop tools to predict the CpG islands segments' methylation states. 


\section{References}

[1] Jei Kim, Jee-Yeon Kim and Jean-Pierre J. Issa, Aging and DNA Methylation, vol. 3. Current Chemical Biology.2009, pp.321-329.

[2] James G.Herman, M.D. and Stephen B. Baylin, M. D. .Gene Silencing in Cancer in Association with Promoter Hypermethylation, vol. 349.The New England Journal of Medicine, 2003, pp: 2042-2054.

[3] Masaki Okano, Shaoping Xie and En Li. Cloning and Characterization of a Family of Novel Mammalian DNA (cytosine-5) Methyltransferases, vol.19. Nature Genetic, 1998, pp: 219-220.

[4] Manel Esteller, Paul G. Corn, Stephen B. Baylin, and James G. Herman. A Gene Hypermethylation Profile of Human Cancer, vol. 61.Perspectives in Cancer Research, 2001, pp: 3225-3229.

[5] Stephen B.Baylin and James G. Herman.DNA Hypermethylation in Tumorigenesis: epigenetic joins genetics, vol. 16.Trends in Genetics, April 2000, pp: 168-174.

[6] Ann S.Wilson, Barbara E.Power and Peter L. Molloy.DNA hypomethylation and human diseases. Biochimica et Biophysica. Acta-Reviews on cancer, January 2007, pp: 38-162.

[7] Bruce Richardson. Impact of aging on DNA methylation, vol. 2. Aging research reviews.2003, pp: 245-261.

[8] Christina Dahl, Per Guldberg .DNA methylation analysis techniques,vol. 4. Biogerontology, 2003, pp: 233-250.

[9] Yan Zhang, Jie Lv, Hongbo Liu, Jiang Zhu, Jiangzhong Su, Qiong Wu,ect.HHMD: the Human Histone Modification Database,vol. 38. Nucleic Acids Research, 2010, pp: D149-D154.

[10] Christoph Grunau, Eric Renault, Andre Rosenthal and Gerard Roizes. MethDB - a public database for DNA methylation data, vol. 29.Nucleic Acids Research, 2001, pp: 270-274.

[11] Mate Ongenaert, Leander Van Neste, Tim De Meyer and Gerben Menschaert, etc. PubMeth: a cancer methylation database combining text-mining and expert annotation, vol. 36. Nucleic Acids Research, 2008, pp: 842-846.

[12] Ximao He, Suhua Chang, Jiajie Zhang, etc. MethyCancer: the database of human DNA methylation and cancer, vol. 36.Nucleic Acids Research, 2008, pp: 836-841.

[13] Celin Amoreira, Winfried Hindermann and Christoph Grunau. An improved version of the DNA methylation database (MethDB), vol. 31.Nucleic Acids Research, 2003, pp: 75-77.

[14] Vincent Negre and Christoph Grunau. The MethDB DAS Server: Adding an Epigenetic Information Layer to the Human Genome. Epigenetics, 2006, pp: 101-105.

[15] Takai D, Jones PA.The CpG island searcher: a new WWW resource, vol.3.In Silico Biol, 2003, pp: 235-240. 